\title{
INTERthesis
}

\section{O FEMININO E O FEMINISMO NAS POESIAS DAS PROFESSORAS POETAS}

The feminine and feminism in the poetry of the Teacher Poets

Cristiane de Mesquita Alves

Doutora em Comunicação, Linguagens e Cultura Professora de Literatura da Universidade do Estado do Pará Pesquisadora do Grupo de Pesquisa Linguagens e Tecnologia

E-mail: cris.tesouro@gmail.com https://orcid.org/0000-0002-1723-9611

A lista completa com informações da autora está no final do artigo

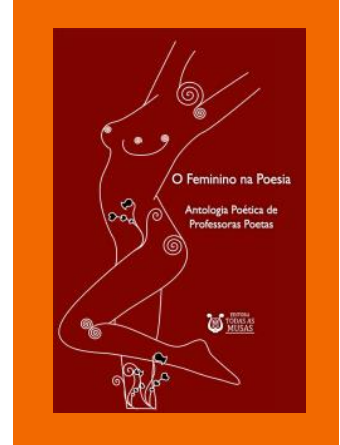

BOTTON, Fernanda Verdasca; BOTTON, Flávio (Orgs). O feminino na poesia: antologia poética de professoras poetas. São Paulo: Todas as Musas, 2018.

PALAVRAS-CHAVE: Feminino. Feminismo. Poesia.

KEYWORDS: Feminine. Feminism. Poetry. 
O livro O feminino na poesia: antologia poética de professoras poetas é composto por vinte e quatro poesias de autoria de professoras poetas, de diferentes lugares do Brasil. Ele é o resultado de um edital lançado em 2018, pela editora Todas as Musas que contemplava uma seleção de textos, em formato de versos, sobre a questão do feminino, do feminismo e assuntos pertinentes à figura da mulher em diversas teorias e abordagens.

A apresentação da obra é feita por um dos organizadores - a professora doutora e editora da Todas as Musas Fernanda Verdasca Botton - a qual faz um breve percurso descritivo das musas inspiradoras da obra de arte ao longo da História do panteão ocidental, sobretudo as greco-romanas, para depois inserir a performance feminina das novas poetas em suas mais variadas manifestações.

O livro não abrange uma sequência temática. No entanto, para uso didático, irá se organizar nesta resenha, uma seleção das poesias por categorias afins que pairam sobre o feminino se considerar a premissa de Tiburi (2018), ao termo que sugere aos atributos dóceis e angelicais das ações femininas, bem como aos traços do feminismo, como comportamentos que se "apresenta [m] como crítica em relação ao patriarcado na forma de Estado, Mídia, Igreja, Família, Capital.” (TIBURI, 2018, p. 50-51), nos quais contemplam a força temática da maioria das poesias escritas por estas professoras, poetas, femininas e feministas.

Nesse sentido, esse livro, por meio de versos curtos, produz um corpus de Literatura feminista por constituir um texto como um todo que lembra o que bell Hooks (2019) escreveu como Educação feminista para um consciência crítica, quando mulheres se dispõem a lutar juntas para recuperar a história das mulheres e conquistar direitos feministas. Lidas dessa maneira, as poesias da coletânea contribuem de modo significativo para divulgar "uma literatura que ajuda a informar uma multidão de pessoas, que ajuda indivíduos a compreenderem o pensamento e as políticas feministas, escrita [s] em uma vasta gama de estilos e formatos." (HOOKS, 2019, 45).

Além disso, essa antologia acaba por se tornar uma Literatura representativa do lugar de fala da mulher através da poesia, por trazer em sua temática aquilo que Ribeiro (2017) entenderia como um dos meios de combater o patriarcalismo, visto como uma "prática no combate às desigualdades, no enfretamento do capitalismo patriarcal e desenvolvendo novas formas de ser mulher." (RIBEIRO, 2017, p. 25). A poesia feminina/ feminista das professoras poetas, então, poderia ser entendida como uma dessas formas de ser mulher e demarcar na escrita essa reivindicação da vez da fala de quem é/seria o sujeito agora (a mulher), não mais o homem. 
Nesse viés, a escrita poética dessas mulheres resulta no pensar a categoria da mulher em seu lugar de fala, reiterando o discurso da visibilidade feminina defendido por Ribeiro (2017). Logo assim, as autoras dessas poesias assumem sua posição de fato que "mulher [é] uma fêmea na medida em que se sente fêmea. [...] Não é a natureza que define a mulher: esta é que se define retomando a natureza em sua afetividade." (BEAUVOIR, 2009, p. 59).

Partindo-se dessa contextualização, essa voz de mulher que vem despertar a mulherificação nos gestos e pelas palavras no dizer de Diniz (2015) sobre a manifestação do feminismo, e confrontar pelas metáforas o falocentrismo, têm-se: Poética da autonomia de Graça Graúna, poema inspirado no livro Pedagogia da autonomia do educador brasileiro Paulo Freire, empregado para apresentar o discurso da mulher como semântica da resistência e da voz da liberdade contra o falo opressor; Caleidoscópio de Andrea de Paula - poesia organizada pelo uso inusitado de brincadeiras entre as letras maiúsculas e minúsculas das palavras - abordando a questão do sexo, da menstruação e da fertilidade femininas em conteúdos poéticos de conscientização, no intuito de desmitificá-los e naturalizá-los, como particularidades comuns na rotina de qualquer mulher.

Colar que não é da tua conta de Evelyn Caroline de Mello, expõe a importância do lugar de fala da mulher, destacando que nem sempre ela estará disposta a ser poesia, canto, delicadeza, leveza e beleza características exigidas pela sociedade patriarcal; mas também, desperta a atenção do leitor para os momentos feios presentes no cotidiano feminino, a exemplo do feminicídio e do suicídio. Outra poesia que dialoga com as sensações e as dores de violência feminina é a Tríptico de uma violência de Julia Larré.

A mulher em constante transformação, comparada a uma fênix renascida, a uma deusa Afrodite ou a uma santa, na premissa metafórica de entender isso, como a força hereditária daquelas que lutaram no passado, mulheres exemplos de lutas, são as temáticas destacadas pelas poesias $A$ mulher que ficou para mim de Cristiane de Mesquita Alves, Mulheres-líquido de Patrícia Anunciada e ... (apenas reticências no título original da poesia) de Debora Oliveira Andrade.

Feminilidade é o assunto central Do berço ao paraíso de Gisele Martins Ferreira, que retrata o percurso poético do corpo da menina em transformação para o corpo da mulher. MDG Ferraz compartilha a experiência do despertar do corpo menina - mulher em $A$ menininha possuía. Maria Antonieta Amarante de Mendonça Cohen também o faz na poesia Cristais, contrapondo o olhar da mulher entre as lágrimas de uma mulher já feita e da menina contrafeita. Assim como Silvia Zanutto em Moça-flor. 
Nesse grupo de poesias, a feminilidade é dosada pela força do erotismo, como uma "maneira de subverter as leis da cultura." (BRANCO, 2004, p. 42), já que os versos expõem uma descrição do corpo feminino - ainda menina - na forma de subversão social, ao desconstruir um perfil de delicadeza imposto à mulher pela sociedade patriarcal. As poetasprofessoras - como o livro designa - empregam títulos irônicos e bem sugestivos para confrontar as verdades do patriarcado, que têm "uma estrutura de crença firmada em uma verdade absoluta, uma verdade que não tem nada de 'verdade', que é antes, produzida na forma de discursos, eventos e rituais." (TIBURI, 2018, p. 27, grifo da autora).

Assim, A menininha possuía satiriza os modos que a menina deveria ter dentro desta ideologia falocêntrica, bem como Cristais (a metáfora que a menina está a ponto de quebrar com o crescimento) e Moça- flor, que não deixa de trazer com o desenvolvimento físico e intelectual, as duas partes da/na mulher: o feminino e o feminismo. Estes dois conceitos não se excluem na obra analisada, pelo contrário, mesclam-se e são necessários para que assim aconteça uma conscientização coletiva da valorização da mulher (HOOKS, 2019), pois, as características da mulher, enquanto corpo e alma estão lá, nela (na mulher), a ponto de serem despertadas por sua vontade, não podendo mais se sujeitar aos desejos exclusivos das necessidades dos homens.

Por outro lado, o que se observa na maioria dos textos é que o feminismo se torna o alvo principal da escrita das autoras do livro, sobressaindo-se diante das passagens remotas, implícitas do imaginário angelical, ideal e fantasioso da beleza e da fragilidade femininas que marcou muitas poesias destinadas a falar de mulher ou acerca dela. Nesse livro, como as vozes poéticas são de mulheres, o lugar de representatividade ganha força, direcionando-se ao fazer poesia com um olhar de lirismo e resistência do feminismo, porque através dele as mulheres terão condições de "questionar os ideais nos quais acreditamos, ao contrário do que imaginamos, serve para nos situar no mundo." (TIBURI, 2018, p. 26).

Também - como forma de homenagem - e, modo de falar das mãos calejadas das mulheres fortes que chegam à velhice, dois textos líricos se destacam: a poesia Cora de Crisley Ladeia, na qual mescla informações de vida e obra da escritora Cora Coralina, atribuindo ao livro, tons de saudosismo e encanto de um tempo especial, derradeiro da vida: a velhice. E, o de Pollyana Aranha, no eu-lírico da influência e da inspiração, presta homenagem à figura grandiosa da mãe, mulher-materna nos versos de Mulher Inspiradora.

A mulher não materna, que não tem intenções de cumprir seu papel social condicionado à estrutura arcaica e patriarcal, desafiando "o lugar subalterno e negativo nessa ordem." (TIBURI, 2018, p. 61) destinado a ela é a discussão levantada no texto de 
Kalliny Rayner Jesus do Carmo, intitulado: Não tenho instinto materno. Outra poesia contrária a esses valores pré-estabelecidos do falocentrismo é Trincar palavras de Betina Ruiz, principalmente por seus versos sugerirem passagens ambíguas, pelo emprego do verbo comer, quando expressa que uma mulher pode comer a outra pelo olhar, e confirma isso a uma amiga - presente em um dos versos.

Nessa linha de raciocínio, de poesias que subvertem e resistem ao que seja superficialmente normal, está $A$ ordem secreta das coisas de Tania Rego. Tania faz um discurso poético crítico-reflexivo sobre os espelhos sociais, ironizando que precisam fazer uma revolução para libertar os vivos e os fantasmas que vivem escondidos na sociedade.

O Ser mulher de Cicília Frazão é uma ode à força do trabalho feminino e ao desdobramento social, do que é ser mulher em uma sociedade que estipula tarefas cotidianas a serem cumpridas. Temática também ressaltada por Elis Regina de oliveira em Lá vem ela! , retratando a rotina árdua de labuta de uma mulher numa pequena narrativa poética.

O fazer poético, em um instinto de metalinguagem é outro aspecto exposto na coletânea, verificado nas poesias: Palavras ao telefone de Ana Boessio, Poeteira de Maiaty Saraiva Ferraz, Sou poesia de Flavia Rohdt e O Belo de Laura Figueiredo. Nessas poesias, as escritoras incidem seus processos de criação literária, pautados no discurso do falar de poesia, descrevendo-a, (re) significando a maneira criativa do cotidiano e metamorfoseando em ações poéticas, demonstrando como o verso chegou ao papel.

$\mathrm{E}$, as duas últimas apresentações das poesias Amormar (Amor e Mar) de Adriana Francisca de Medeiros e Acabou de Marisa Guedes representam o eu-lírico feminino melancólico, choroso e triste pela ausência de um amor indefinido, além de um diálogo dolorido e solitário compartilhado com os elementos da natureza, de modo a compensar a companhia de alguém que se foi.

Diante desse panorâmico do livro, o que se observa pelas leituras é que os eu-líricos (das autoras), conscientes da importância da valorização da mulher, dos direitos e deveres, buscam despertar nos seus leitores de um modo amplo, também este olhar de conscientização feminista.

Ao abordar temas envolvendo o feminino em diferentes vieses: infância, puberdade (passagem de transformação do corpo menina - mulher como elas preferem escrever), velhice, trabalho, sexualidade, homossexualidade/lesbianismo, sozinhas ou acompanhadas, etc., essas mulheres, poetas e professoras procuram, com base nos seus versos, entender como a dominação do masculino e do sexismo são expressos ainda na 
sociedade de forma muito intensa no dia a dia, e, que, muitas vezes, acabam por provocar diretamente o feminicídio e a violência doméstica em números alarmantes diariamente.

Logo, é por essas breves informações a respeito desta antologia, descritas neste estudo, que se considera ela como uma leitura fundamental no que se refere ao feminino, ao feminismo, a partir de várias maneiras de se abranger o tema mulher. É um livro de poesias. É um livro de consciência feminista, escrito por aquelas que veem e entendem muito bem qual o lugar de fala da mulher na sociedade, que lutam por direitos igualitários aos homens e que desafiam o leitor a ler este tema por um livro breve, crítico, mas, ao mesmo tempo, cheio de encanto proveniente do próprio processo de se fazer poesia.

\section{REFERÊNCIAS}

BEAUVOIR, Simone de. O segundo sexo. Trad. Sérgio Milliet. $2^{\underline{a}}$ ed. Rio de Janeiro: Nova Fronteira, 2009.

BOTTON, Fernanda Verdasca; BOTTON, Flávio (Orgs). O feminino na poesia: antologia poética de professoras poetas. São Paulo: Todas as Musas, 2018.

BRANCO, Lucia Castello. O que é erotismo. $2^{\underline{a}}$ ed. $1^{\text {a }}$ reimp. São Paulo: Brasiliense, 2004. (Coleção Primeiros Passos, 136).

DINIZ, Débora. Feminismo: modo de ver e mover-se. In: SERRA, Carlos (Org). O que é feminismo? Cadernos de Ciências Sociais. Lisboa: Escolar Editora, 2015.

HOOKS, bel. O feminismo é para todo mundo: políticas arrebatadoras. $8^{a}$ ed. Trad. Bhuvi Libânio. Rio de Janeiro: Rosa dos tempos, 2019.

RIBEIRO, Djamila. O que é lugar de fala? Belo Horizonte: Letramento/Justificando, 2017.

TIBURI, Márcia. Feminismo em comum: para todos, todes e todos. $8^{\mathrm{a}}$ ed. Rio de Janeiro: Rosa dos Tempos, 2018.

\section{NOTAS}

\section{Cristiane de Mesquita Alves}

Doutora em Comunicação, Linguagens e Cultura (PPGCLC Unama/Bolsista PROSUP/CAPES). Professora de Literatura da Universidade do Estado do Pará (UEPA). Pesquisadora do Grupo de Pesquisa Linguagens e Tecnologia (UEPA/CNPq). E-mail: cris.tesouro@gmail.com

https://orcid.org/0000-0002-1723-9611

Endereço de correspondência do principal autor

Universidade do Estado do Pará. Campus I - CCSE. Rua do Una -181/182. Telégrafo, 66050540 - Belém, PA - Brasil.

\section{AGRADECIMENTOS}

Editora Todas as Musas 
CONTRIBUIÇÃO DE AUTORIA

Não se aplica

CONJUNTO DE DADOS DA PESQUISA

1) Todo o conjunto de dados que se dá suporte aos resultados deste estudo foi publicado no próprio artigo.

\section{APROVAÇÃO DE COMITÊ DE ÉTICA}

Não se aplica

\section{CONFLITO DE INTERESSES}

Não se aplica

\section{LICENÇA DE USO}

Os autores cedem à Revista Internacional Interdisciplinar INTERthesis os direitos exclusivos de primeira publicação, com o trabalho simultaneamente licenciado sob a Licença Creative Commons Attribution (CC BY) 4.0 International. Esta licença permite que terceiros remixem, adaptem e criem a partir do trabalho publicado, atribuindo o devido crédito de autoria e publicação inicial neste periódico. Os autores têm autorização para assumir contratos adicionais separadamente, para distribuição não exclusiva da versão do trabalho publicada neste periódico (ex.: publicar em repositório institucional, em site pessoal, publicar uma tradução, ou como capítulo de livro), com reconhecimento de autoria e publicação inicial neste periódico.

\section{PUBLISHER}

Universidade Federal de Santa Catarina. Programa de Pós-graduação Interdisciplinar em Ciências Humanas. Publicação no Portal de Periódicos UFSC. As ideias expressadas neste artigo são de responsabilidade de seus autores, não representando, necessariamente, a opinião dos editores ou da universidade.

\section{EDITORES}

Javier Ignacio Vernal e Silmara Cimbalista

\section{HISTÓRICO}

Recebido em: 12-02-2020 - Aprovado em: 14-03-2020 - Publicado em: 23-11-2020 